\title{
FATORES CRÍTICOS DE SUCESSO DA REDE DE INCUBAÇÃO DE EMPREENDIMENTOS DO IFES
}

\author{
CRITICAL SUCCESS FACTORS OF THE INCUBATION NETWORK OF ENTERPRISES OF THE IFES
}

FACTORES CRÍTICOS DE ÉXITO PARA LA RED DE INCUBACIÓN EMPRESARIAL DE IFES

\author{
(D) João Paulo do Carmo ${ }^{1}$ \\ Rodolpho da Cruz Rangel ${ }^{2}$
}

\begin{abstract}
Cite as - American Psychological Association (APA)
Carmo, J. P., \& Rangel, R. da C. (2020, May/Aug.). Fatores críticos de sucesso da rede de incubação de empreendimentos do IFES. International Journal of Innovation - IJI, São Paulo, 8(2), 150-175.

https://doi.org/10.5585/iji.v8i2.17390.
\end{abstract}

\section{Resumo}

Este trabalho intitulado "Fatores Críticos de Sucesso da Rede de Incubação de Empreendimentos do Ifes." tem como principal objetivo identificar os fatores críticos de sucesso da referida rede de incubação do Ifes, para tanto foi realizado um estudo de caso único, na incubadora do Ifes, utilizando análise documental e a entrevista semiestruturada. A relevância deste estudo encontra-se na aplicação de elementos teóricos e na investigação científica das incubadoras de empreendimentos enquanto ambientes especializados em apoiar empreendimentos que estão em fase inicial de desenvolvimento do seu produto ou protótipo. Fatores Críticos de Sucesso são as competências adquiridas por um gestor ou por sua equipe de trabalho, que conduzirá a organização ao sucesso. Os principais resultados encontrados neste estudo foram, que os fatores críticos de sucesso são as variáveis determinantes para manter as incubadoras de empresas competitivas, melhorando seus processos organizacionais e garantindo sua sobrevivência. Dentre os fatores identificados destacam-se: o suporte financeiro e apoio governamental do estado do Espírito Santo, apoio institucional do Ifes, suporte técnico e tecnológico, gestão dos processos da incubadora e o acompanhamento das empresas incubadas. As principais implicações teóricas e metodológicas deste estudo indicam que promover a gestão de ambientes inovadores requer condições para aplicação dos fatores criticos e conciliação de novas ferramentas para gestão. Com essa pesquisa espera-se contribuir com a abertura de outros estudos, além de ser um instrumento de base teórico e metodológico para que as incubadoras de empresas possam oferecer melhores retornos com impacto positivo junto a sociedade.

Palavras-Chave: Instituto Federal. Incubadora. Rede de incubação de empreendimentos. Fatores críticos de sucesso. IRAMUTEQ.

\footnotetext{
${ }^{1}$ Universidade Federal do Espírito Santo (UFES), Vitória, Espírito Santo - Brasil. joao.carmo@ifes.edu.br

${ }^{2}$ Universidade Federal do Rio de Janeiro (UFRJ), Rio de Janeiro, Rio de Janeiro - Brasil. rrangel@ifes.edu.br
} 


\begin{abstract}
This paper entitled "Critical Success Factors of the Incubation Network of Enterprises of the Ifes." has as main objective of this study was to identify the critical success factors of the entrepreneurship incubation network of the Federal Institute of Espírito Santo. So it was done a single case study was conducted in the Ifes incubator, using documentary analysis and the semi-structured interview. The relevance of this study is found in the application of theoretical elements and in the scientific investigation of Entrepreneurs incubators as environments specialized in supporting projects that are in the early stages of development of your product or prototype. Critical Success Factors are the skills acquired by a manager or his or her work team, who will lead the organization to success. The main results found in this study were, critical success factors are the determining variables to keep incubators competitive, improving their organizational processes and ensuring their survival. Among the identified factors are: financial support and government support of the state of Espírito Santo, institutional support of Ifes, technical and technological support, management of incubator processes and monitoring of incubated companies. The main theoretical and methodological implications of this study indicate that promoting the management of innovative environments requires conditions for application this critical factors and reconciling new management tools. This research is expected to contribute to the opening of other studies, in addition to being an instrument of theoretical and methodological basis so that business incubators can offer better returns with a positive impact on society.
\end{abstract}

Keywords: Federal Institute. Incubator. Business incubation network. Critical success factors. IRAMUTEQ.

\title{
Resumen
}

Este trabajo titulado "Factores críticos de éxito de la red de incubación empresarial de Ifes". tiene como objetivo principal identificar los factores críticos de éxito de la red de incubación de Ifes, para ello se realizó un estudio de caso único en la incubadora de Ifes, mediante análisis documental y entrevista semiestructurada. La relevancia de este estudio se encuentra en la aplicación de elementos teóricos y en la investigación científica de las incubadoras de empresas como entornos especializados en el apoyo a empresas que se encuentran en la etapa inicial de desarrollo de su producto o prototipo. Los Factores Críticos de Éxito son las habilidades adquiridas por un gerente o su equipo de trabajo, que llevarán a la organización al éxito. Los principales resultados encontrados en este estudio fueron, que los factores críticos de éxito son las variables determinantes para mantener competitivas a las incubadoras de empresas, mejorando sus procesos organizacionales y asegurando su supervivencia. Entre los factores identificados, se destacan: apoyo financiero y apoyo gubernamental del estado de Espírito Santo, apoyo institucional de Ifes, apoyo técnico y tecnológico, gestión de los procesos de la incubadora y seguimiento de las empresas incubadas. Las principales implicaciones teóricas y metodológicas de este estudio indican que promover la gestión de entornos innovadores requiere condiciones para la aplicación de factores críticos y la conciliación de nuevas herramientas de gestión. Con esta investigación se espera contribuir a la apertura de otros estudios, además de ser un instrumento de base teórica y metodológica para que las incubadoras de empresas puedan ofrecer mejores rendimientos con un impacto positivo en la sociedad.

Palabras clave: Instituto Federal. Incubadora. Red de incubación empresarial. Factores críticos del éxito. IRAMUTEQ. 


\section{Introdução}

Baron e Tang (2009) assumem que a criatividade é um dos fatores que contribuem para a inovação. Toda inovação começa com ideias criativas e estas são determinantes para que a inovação aconteça (MARTÍNEZ-ROMÁN, et al., 2011). Romero e Martínez-Román (2012) afirmam que existe um esforço por parte do governo para apoiar o empreendedorismo e a inovação nas pequenas e médias empresas.

No Brasil, a Lei de Inovação nº 10.793 de 2 de dezembro de 2004, foi criada com o objetivo de dar suporte à inovação. A lei menciona que toda Instituição de Ciência e Tecnologia (ICT) precisa de um núcleo de inovação tecnológica (NIT) para apoiar e gerir sua política de inovação, a fim de proteger as pesquisas realizadas nas instituições de ensino, bem como fazer a intermediação entre a academia e o mercado.

Com o movimento, um outro marco importante foi a criação do fórum dos Gestores de Inovação e Transferência de Tecnologia (FORTEC), com o intuito de realizar eventos que reunissem gestores de NIT para trocar experiências e disseminar ainda mais a cultura de inovação no país. Em sua estrutura, o FORTEC é composto por 264 NIT's credenciados e 166 NIT's implementados (Relatório Anual FORTEC 2014-15). As incubadoras, geralmente ligadas a algum NIT, são ambientes que propiciam a formação de projetos inovadores, com desenvolvimento de produtos e serviços de alto valor agregado.

De acordo com um estudo realizado em 2016 pela ANPROTEC, em parceria com o SEBRAE, o Brasil tem 369 incubadoras em operação, que abrigam 2.310 empresas incubadas e 2.815 empresas graduadas, gerando 53.280 postos de trabalho. O faturamento das empresas apoiadas por incubadoras ultrapassa os R $\$ 15$ bilhões (ANPROTEC, 2016).

O NIT do Instituto Federal do Espírito Santo (Ifes) é denominado de Agência de Inovação (Agifes). É um órgão gerenciado pela Diretoria de Extensão Tecnológica - DIREX, vinculada à Pró-Reitoria de Extensão (Proex). Esta agência tem como missão gerenciar as políticas públicas de inovação e desenvolver as ações voltadas para o desenvolvimento regional por meio da capilaridade do Ifes. As principais atividades desenvolvidas pela Agifes encontram-se sustentadas em 03 (três) segmentos: Incubadora e sua Rede de Incubação de Empreendimentos; Propriedade Intelectual, e Serviços Tecnológicos.

Segundo Al-Mubaraki e Busler (2011), as incubadoras têm a função de amadurecer e desenvolver ideias a partir do seu programa de incubação de empreendimentos. Dessa forma ela dá o suporte tecnológico necessário visando seu desempenho e crescimento. Dentre as principais funções que as incubadoras oferecem destacam-se as parcerias com outras empresas, 
fortalecimento de redes de relacionamentos e diversos tipos de consultorias (RATINHO; HENRIQUES, 2010).

Redes de inovação são vistas como interconexões de processos de interação entre atores sociais heterogêneos produzindo inovações. Ou seja, trata-se de uma estrutura social, geralmente auto-organizada, criada em uma situação instável porque os atores envolvidos (empresas, universidades e agências governamentais) não podem definir o problema de inovação ou sua solução por si (Pyka, 2000).

A rede é um modo de organizar as atividades sociais que oferece forma condições para a potência criativa de cooperação social, ela não pode se limitar a uma instituição e ser submetida ao seu controle hierárquico (Corsani, 2003). Essa rede está definida nas conexões estabelecidas por atores que formam um grupo coeso que compartilham de um objetivo comum de promover inovação e inovar no poder público, tanto em relações dualistas (entre apenas dois pontos/atores) ou em relações multifocais (entre três ou mais atores).

Considerando o papel fundamental das incubadoras de empresas e reconhecendo os fatores críticos de sucesso como parâmetros norteadores para tomada de decisão dos gestores, o presente estudo busca discutir na rede de incubação de empreendimentos do Ifes quais são esses fatores críticos de sucesso, visto que os fatores são fortemente influenciados pela região em que se encontra os núcleos incubadores, governo, cultura e economia local.

O objetivo deste estudo é identificar os fatores críticos de sucesso da rede de incubação de empreendimentos do Instituto Federal do Espírito Santo, segundo a percepção dos gestores dos núcleos incubadores, empreendedores incubados e servidores do Ifes ligados à incubadora.

No Brasil, foram identificados poucos estudos que avaliam os fatores críticos de sucesso em incubadoras. Apenas um artigo de autoria de Barbosa et al. (2014), tratou dos fatores críticos de sucesso de incubadoras de empresas de Pernambuco. Quando a pesquisa se restringe ao estado do Espírito Santo, foi encontrado apenas um artigo sobre o tema incubadora. Logo, existe uma escassez de estudos que tratam das questões relacionadas às incubadoras capixabas.

Segundo dados do Relatório Estratégico do Governo do Estado do Espírito Santo (2015), a economia do estado, de 2001 a 2012, se tornou a quinta melhor do país. Já a área de Ciência, Tecnologia e Inovação (CT\&I), possui dificuldades em promover oportunidades de negócios e gerar emprego e renda para a população capixaba. Dados do Relatório Estratégico do Governo (2015), em 2010, o investimento em CT\&I representou apenas 0,10\% do PIB do estado do Espírito Santo. 
Diante do que foi citado, surgiu, então, a ideia de se realizar um estudo que faça a análise dos fatores críticos de sucesso da rede de incubação de empreendimentos do Instituto Federal do Espírito Santo. Em nível estadual, o estudo pode contribuir com as discussões a respeito das peculiaridades e dos fatores críticos de cada região onde os núcleos incubadores estão espalhados.

\section{Referencial teórico}

Inovação tecnológica e os núcleos de inovação tecnológica

Segundo Schumpeter (1984), em sua Teoria do Desenvolvimento Econômico, foi o capitalismo que impulsionou o surgimento de empreendedores criativos e inovadores, que, por meio de seus conhecimentos, foram os responsáveis pelos avanços tecnológicos.

De acordo com Armbruster et al. (2008), Martínez-Román, Gamero e Tamayo (2011) e Fitjar e Rodríguez-Pose (2013), a inovação tem relação direta com os resultados de P\&D nas indústrias. Além disso, a inovação também possui uma forte dependência dos recursos e capacidades em cada organização (TRIGUERO; CÓRCOLES, 2013).

Um Sistema Nacional de Inovação (SNI) é formado por instituições públicas e privadas que têm como objetivo ajudar essas instituições a promover o desenvolvimento científico e tecnológico do país, ou seja, a disseminar a inovação (NELSON, 1993). Os indicadores empresariais são de suma importância para garantir a manutenção das informações dentro do SNI (FUJINO; STAL, 2005).

A Lei de Inovação (Lei 10.973/04, regulamentada pelo Decreto 5.563, de 11/10/2005), foi criada com o objetivo de dar suporte às pesquisas científicas com vistas ao desenvolvimento industrial do país. A lei deve estimular a geração de patentes e a transferência de tecnologia das instituições públicas de ensino para o mercado, flexibilizando toda a gestão do licenciamento da propriedade intelectual.

É notório o esforço do Governo brasileiro em lançar programas de financiamento que ajudam a cooperação entre instituições e setor privado, visando o desenvolvimento de inovações. A importância desses programas brasileiros é mencionada por Torkomian e Calligaris (2003), que defendem que a indústria brasileira precisa se tornar mais competitiva e, para isso, os empresários devem procurar os Institutos Federais de Educação, Ciência e Tecnologia como suporte para auxiliar nesse processo.

De acordo com a Lei de Inovação, cada NIT deve dispor de competências e conhecer as regras de cada ICT, para poder cumprir as solicitações demandadas por pesquisadores e grupos 
de pesquisa. O objetivo da legislação existente é promover o desenvolvimento de novas tecnologias e incentivar sua proteção. Tudo isso para que os depósitos de patentes brasileiras aumentem e o país possa ser mais competitivo (SOUZA, 2011).

Diante desse contexto, um NIT possibilita um ambiente propício à geração de novas tecnologias, e as ICT são as responsáveis pela proteção e transferência tecnológicas. O núcleo de inovação se torna um mediador entre instituições, o setor privado e a comunidade (SANTOS, 2009).

Um núcleo de inovação não deve ser criado para simplesmente depositar e gerir as patentes dos pesquisadores das próprias instituições. Necessita de uma interação entre a academia e a indústria. Carmo e Costa (2016) destacam a importância em se ter uma incubadora de empresas integrada ao NIT, para ajudar nessas questões.

\section{Incubadoras}

As incubadoras de empreendimentos são ambientes especializados em apoiar empreendimentos que estão em fase inicial de desenvolvimento do seu produto ou protótipo. Oferecem facilidades, serviços de apoio e consultorias, conhecimento de mercado, desenvolvimento das novas tecnologias, apoio legal e acesso a fontes de financiamento, com o objetivo de promover sinergias entre as empresas incubadas.

Um dos primeiros estudos registrados sobre incubadoras de empresas, segundo Bruneel et al. (2012), deu-se na cidade de Nova York, nos Estados Unidos, em 1959. Os programas de incubação surgiram no final dos anos 1970, e até a década de 1980, apenas um pequeno número de incubadoras tinha o processo de incubação nos seus negócios (AERNOUDT, 2004). Dados mais recentes, divulgados por Cooper, Hamel e Connaughton (2012), apontam que existam aproximadamente 5.000 incubadoras espalhadas pelo mundo. Dentre essas, cerca de 900 estão instaladas na Europa, e 1.400 estão nos Estados Unidos (BRUNEEL; et al., 2012).

Segundo a Associação Nacional de Entidades Promotoras de Empreendimentos de Tecnologias Avançadas (ANPROTEC, 2015), no Brasil, as primeiras iniciativas datam de 1985, quando foi fundada a primeira incubadora de empresas em São Carlos. Mas foi em 1997 que o movimento ganhou importância, com a realização do Seminário Internacional de Parques Tecnológicos, no Rio de Janeiro (DORNELAS, 2002).

As incubadoras de empresas são ambientes inovativos que fomentam o empreendedorismo. Além disso, têm a função de gerar novos projetos, novas ideias que irão se 
transformar em empresas de sucesso no mercado, criando novos empregos qualificados, buscando desenvolver produtos e serviços com alto valor agregado (BOLLINGTOFT, 2012).

Incubadoras são ambientes de incentivo e apoio logístico, gerencial e tecnológico ao empreendimento. Têm como objetivo apoiar a implantação de novas empresas que tenham como estratégia de negócios a inovação tecnológica. Dessa forma, a incubadora disponibiliza aos empreendedores espaço físico individual para abrigar as empresas temporariamente, espaço físico para uso compartilhado com outros empreendimentos, recursos humanos, serviços especializados para auxiliar as empresas em suas atividades, além de acesso a laboratórios (MCTI, 2013).

Para Al-Mubaraki e Busler (2011), o principal objetivo de uma incubadora de empresas é amadurecer as ideias de empresas nascentes, por um sólido programa de incubação, para ajudar no suporte tecnológico de seu empreendimento, visando seu desempenho e crescimento.

Há diversos tipos de relações entre a academia, indústria e Governo. Essas diferenças acontecem devido aos diferentes tipos de incubadoras existentes e seus objetivos. Cada uma das três entidades desempenha um papel crucial na sociedade, e essas interações criam novos meios de proporcionar maior efetividade das incubadoras. Este arranjo foi denominado de tripla hélice no Brasil (ETZKOWITZ; MELLO; ALMEIDA, 2005).

Dados da ANPROTEC (2015) mostram que 40\% das incubadoras brasileiras são de base tecnológica, $18 \%$ são tradicionais, $18 \%$ são mistas, $2 \%$ são de base cultural, $7 \%$ são de base social, 7\% são de setores agroindustriais e 8\% são incubadoras com foco em serviços.

O principal motivo de investir dinheiro público em incubadoras de empresas, independente do seu tipo, é que as empresas que passaram por um processo de incubação têm um potencial enorme de se sustentar no mercado, gerar emprego e renda, e desenvolver a região onde está inserida. Além disso, os políticos acreditam que essas empresas devem diversificar a economia local com suas novas tecnologias, transferir essas tecnologias das universidades para grandes empresas, visando o desenvolvimento do país em geral (TAVOLETTI, 2013).

\section{Fatores críticos de sucesso nas incubadoras}

Fatores Críticos de Sucesso são as características que influenciam diretamente em uma organização, permitindo que essas características sejam suficientes para assegurar o bom funcionamento da organização, e, assim, torná-la mais robusta e competitiva perante o mercado (MORIOKA; CARVALHO, 2014). 
Segundo Padrão (2011), Fatores Críticos de Sucesso são as competências adquiridas por um gestor ou por sua equipe de trabalho, que conduzirá a organização ao sucesso. Assim, entende-se que os Fatores Críticos de Sucesso consistem em elementos essenciais para alcançar os objetivos no plano executivo, estratégico ou tático de uma organização, e que sustentam um bom desempenho competitivo.

De acordo com as literaturas pesquisadas, pode-se identificar diversos fatores críticos de sucesso. O Quadro 1 apresenta de forma resumida os fatores críticos de sucesso e seus respectivos autores que os identificaram.

Tabela 1 - Fatores Críticos de Sucesso em Incubadoras

\begin{tabular}{|c|c|c|}
\hline \# & Fatores Críticos de Sucesso & Autores \\
\hline 1 & $\begin{array}{l}\text { Infraestrutura e espaços } \\
\text { compartilhados. }\end{array}$ & $\begin{array}{l}\text { Ortigara et al. (2011); Lee e Osteryoung (2004); Buys e } \\
\text { Mbewana (2007); Gillotti e Ziegelbauer (2006); Maletz e } \\
\text { Siedenberg (2007); Lalaka (1996); Gozali et al. (2016). }\end{array}$ \\
\hline 2 & Estratégias de marketing & Ortigara et al. (2011); Maletz e Siedenberg (2007). \\
\hline 3 & Gestão dos processos & $\begin{array}{l}\text { Ortigara et al. (2011); Lee e Osteryoung (2004); Buys e } \\
\text { Mbewana (2007); Gillotti e Ziegelbauer (2006); Maletz e } \\
\text { Siedenberg (2007); Gozali et al. (2016). }\end{array}$ \\
\hline 4 & $\begin{array}{l}\text { Qualificação dos } \\
\text { colaboradores }\end{array}$ & $\begin{array}{l}\text { Ortigara et al. (2011); Buys e Mbewana (2007); Maletz e } \\
\text { Siedenberg (2007); Dornelas (2002); Lalaka (1996). }\end{array}$ \\
\hline 5 & $\begin{array}{l}\text { Incubação à distância } \\
\text { (empreendimentos não } \\
\text { residentes) }\end{array}$ & Ortigara et al. (2011). \\
\hline 6 & Gestão participativa & $\begin{array}{l}\text { Ortigara et al. (2011); Lee e Osteryoung (2004); Buys e } \\
\text { Mbewana (2007); Dornelas (2002). }\end{array}$ \\
\hline 7 & Apoio do Governo & Sun (2007); Dornelas (2002). \\
\hline 8 & $\begin{array}{l}\text { Geração de novos produtos } \\
\text { tecnológicos }\end{array}$ & Sun (2007). \\
\hline 9 & $\begin{array}{l}\text { Suporte financeiro e } \\
\text { financiamentos }\end{array}$ & $\begin{array}{l}\text { Sun (2007); Lee e Osteryoung (2004); Smilor (1987); Buys e } \\
\text { Mbewana (2007); Gillotti e Ziegelbauer (2006); Maletz e } \\
\text { Siedenberg (2007); Lalaka (1996); Gozali et al. (2016). }\end{array}$ \\
\hline
\end{tabular}




\begin{tabular}{|c|c|c|}
\hline$\#$ & Fatores Críticos de Sucesso & Autores \\
\hline 10 & Planejamento estratégico & $\begin{array}{l}\text { Ortigara et al. (2011); Lee e Osteryoung (2004); Buys e } \\
\text { Mbewana (2007); Gillotti e Ziegelbauer (2006); Maletz e } \\
\quad \text { Siedenberg (2007); Dornelas (2002); Lalaka (1996). }\end{array}$ \\
\hline 11 & $\begin{array}{l}\text { Redes de relacionamento } \\
\text { (institucionais, } \\
\text { empreendedores incubados, } \\
\text { empresariais). }\end{array}$ & $\begin{array}{l}\text { Sun (2007); Lee e Osteryoung (2004); Smilor (1987); Buys e } \\
\text { Mbewana (2007); Anholon e Silva (2015); Maletz e } \\
\text { Siedenberg (2007); Dornelas (2002); Lalaka (1996); Gozali } \\
\text { et al. (2016). }\end{array}$ \\
\hline 12 & $\begin{array}{l}\text { Consultorias (contábil, } \\
\text { financeira, jurídica e de } \\
\text { mercado) }\end{array}$ & $\begin{array}{l}\text { Lee e Osteryoung (2004); Gillotti e Ziegelbauer (2006); } \\
\text { Maletz e Siedenberg (2007); Gozali et al. (2016). }\end{array}$ \\
\hline 13 & Gestor da incubadora & Gillotti e Ziegelbauer (2006); Dornelas (2002). \\
\hline 14 & $\begin{array}{l}\text { Acompanhamento das } \\
\text { empresas incubadas }\end{array}$ & Anholon e Silva (2015). \\
\hline 15 & Autossustentabilidade & Anholon e Silva (2015); Dornelas (2002). \\
\hline 16 & Cultura empreendedora & Maletz e Siedenberg (2007); Lalaka (1996). \\
\hline 17 & Apoio da comunidade local & $\begin{array}{l}\text { Lee e Osteryoung (2004); Smilor (1987); Maletz e } \\
\text { Siedenberg (2007); Lalaka (1996). }\end{array}$ \\
\hline 18 & $\begin{array}{l}\text { Apoio técnico e treinamento } \\
\qquad \text { empresarial aos } \\
\text { empreendedores incubados }\end{array}$ & $\begin{array}{l}\text { Sun (2007); Lee e Osteryoung (2004); Smilor (1987); Lalaka } \\
\qquad(1996) .\end{array}$ \\
\hline
\end{tabular}

Fonte: Elaboração própria (2016).

Fatores críticos de sucesso definem áreas-chave de desempenho que são essenciais para que a organização atinja sua missão. Os gestores sabem da importância dessas áreas-chave quando estão à frente das ações de uma incubadora. Qualquer atividade realizada deve levar em consideração esses fatores críticos de sucesso e essas áreas que fazem parte, caso contrário, a organização fica comprometida, deixando de atingir suas metas e, consequentemente, falhando na sua missão.

Foi evidenciado a quantidade de fatores críticos de sucesso observados na literatura. Eles estão ligados tanto a aspectos internos, quanto a aspectos externos a uma incubadora de 
empreendimentos. Além disso, as incubadoras públicas não são economicamente sustentáveis, existe uma dependência financeira dentro das ICT's (CASTRO; SOUZA, 2012). Geralmente, o NIT recebe em torno de $0,1 \%$ do orçamento total disponibilizado para a instituição e este problema afeta diretamente as ações das incubadoras (CARMO; COSTA, 2016).

A metodologia a seguir investigará, através de análise, um estudo de caso em uma rede de incubação de empreendimentos, utilizando análise documental e a entrevista semiestruturada. Os dados serão examinados pela técnica de análise de conteúdo, com o apoio do software IRAMUTEQ. Este software ajudará a identificar os fatores críticos de sucesso da rede de incubação de empreendimentos da incubadora do Ifes e permitirá construir um modelo teórico voltado para a realidade desta rede.

\section{Metodologia}

A pesquisa caracteriza-se como estudo de caso único, de caráter qualitativo, descritivo e exploratório. A triangulação dos dados coletados utilizou duas técnicas: entrevista e a pesquisa documental. As entrevistas foram efetuadas nos meses de agosto de 2016 a maio de 2017. A análise documental foi realizada na rede de incubação de empreendimento do Ifes e se baseou nas seguintes fontes: boletins informativos, editais de seleção de empresas, editais de fomento, convênios diversos, atas de reuniões, relatórios de gestão das incubadoras, dentre outros. Estes arquivos ajudaram no levantamento das informações e para entender as especificidades e dificuldades encontradas na rede.

Para analisar o conteúdo da entrevista semiestruturada, o método utilizado foi a análise de conteúdo (BARDIN, 2004). As dez entrevistas foram transcritas para o formato de texto para serem analisadas pelo software IRAMUTEQ (Interface de $R$ pour les Analyses Multidimensionnelles de Textes et de Questionnaires), de análise lexical das palavras presentes nas falas dos entrevistados. A escolha do software IRAMUTEQ se deu pelo fato dele ser um software gratuito, sem custo para o usuário. Além disso, o IRAMUTEQ é desenvolvido em regime open source (código aberto) e distribuído livremente (software livre).

A pesquisa em questão analisou os fatores críticos de sucesso da rede de incubação de empreendimentos do Ifes segundo a percepção dos gestores dos núcleos incubadores, empreendedores incubados e servidores do Ifes ligados à incubadora, através de dois questionamentos. Primeiro, foi perguntado quais seriam os fatores críticos de sucesso da incubadora ligada ao entrevistado. Posteriormente o pesquisador perguntou a opinião do entrevistado em relação aos fatores críticos de sucesso identificados na revisão de literatura e 
não mencionado na resposta à primeira pergunta. As categorias e subcategorias forma definidas a posteriori (BARDIN, 2004).

\section{Apresentação dos resultados}

Rede de incubação de empreendimentos

A Incubadora do Instituto federal do Espírito Santo (Ifes) é reconhecida pelo trabalho de integração em rede de núcleos incubadores, com vista em promover o desenvolvimento de competências (conhecimentos, habilidades e atitudes) empreendedoras e atividades inovativas que contemplam alunos, servidores (docentes e técnicos) e comunidade externa. Encontra-se institucionalizada pela resolução do Conselho Superior n. ${ }^{\circ}$ 70/2011, de 08 de dezembro de 2011, que define regras e procedimentos para a institucionalização destes referidos núcleos, localizados nos campi do Ifes, que podem gerar um trabalho em caráter de base tecnológica, social e cultural.

A Rede de Incubação de Empreendimentos constitui-se em um programa de atividades que se encontram institucionalizados e oferecem caminhos para o cumprimento da missão do Ifes na sociedade, é desenvolvido e gerenciado pela Agência de Inovação do Ifes (Agifes), com o objetivo de articular, integrar e oferecer suporte às atividades desenvolvidas pelos núcleos incubadores do Ifes.

As atividades, processos, e projetos institucionais desenvolvidos pelos núcleos incubadores estão diretamente relacionados com a função estratégica, integradora e articuladora deste Programa em Rede de Incubação de Empreendimentos do Ifes. Abaixo é possível visualizar a sistematização do programa mencionado. 
Figura 1 - Relação do Programa Institucional em Rede de Incubação de Empreendimentos com os Núcleos Incubadores e seus processos

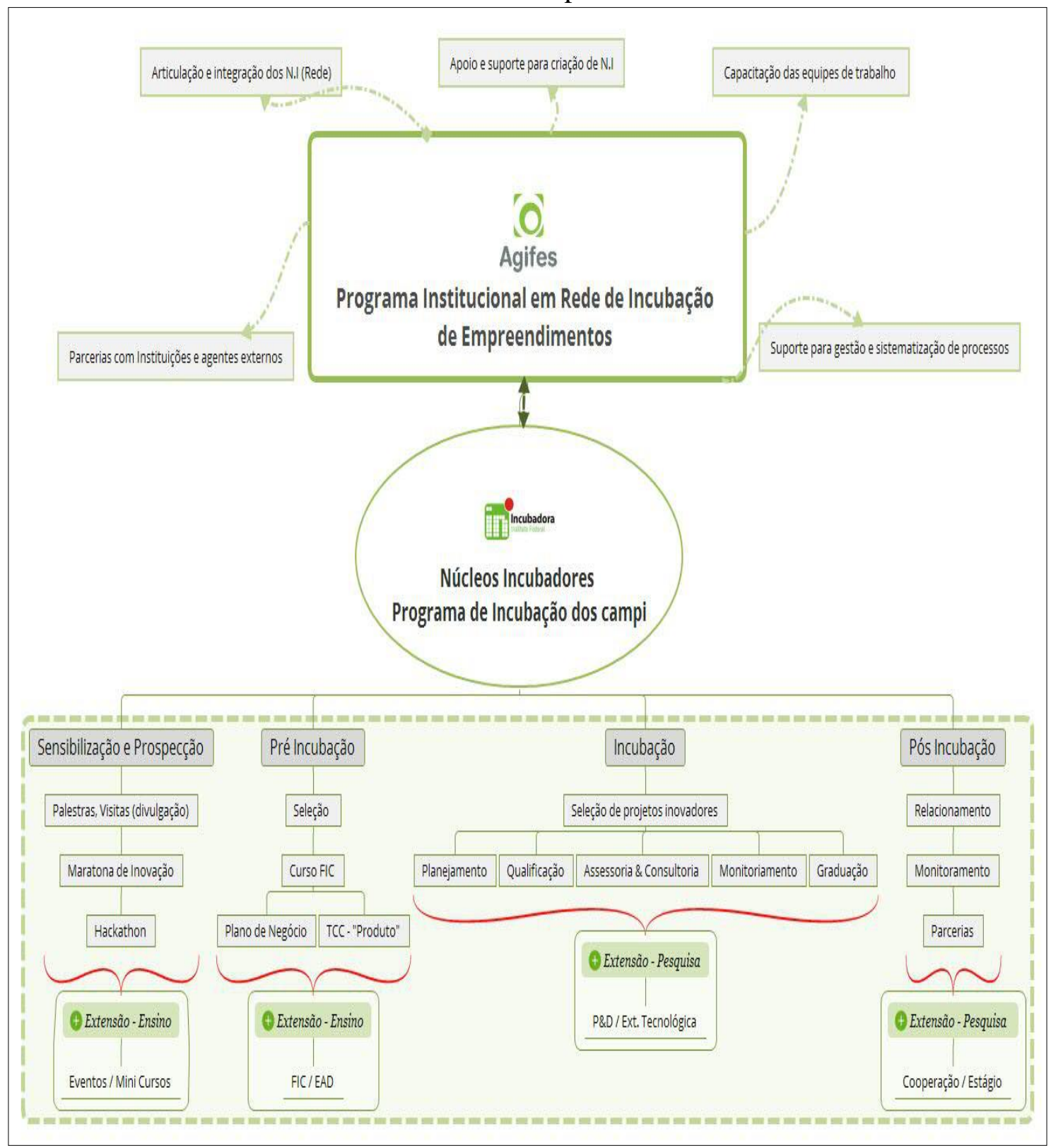

Fonte: Elaborado pelos autores (2017).

A Rede de Incubação de Empreendimentos oferece este conjunto de apoio para a gestão dos núcleos incubadores, e realiza: Suporte para a criação de novos núcleos incubadores; Capacitação das equipes de trabalho integrantes da rede; parcerias e acordos com instituições e agentes externos; sistematização de processos. Essas atividades são realizadas pela Gestão Sistêmica da Rede de Incubação de Empreendimentos (inserida na Agifes), que por sua vez busca promover caminhos para a interação e troca de informações com as equipes de gestão nos núcleos incubadores que estão localizados conforme demonstra o mapa: 
Figura 2 - Mapa da Rede de Incubação de Empreendimentos (2017)

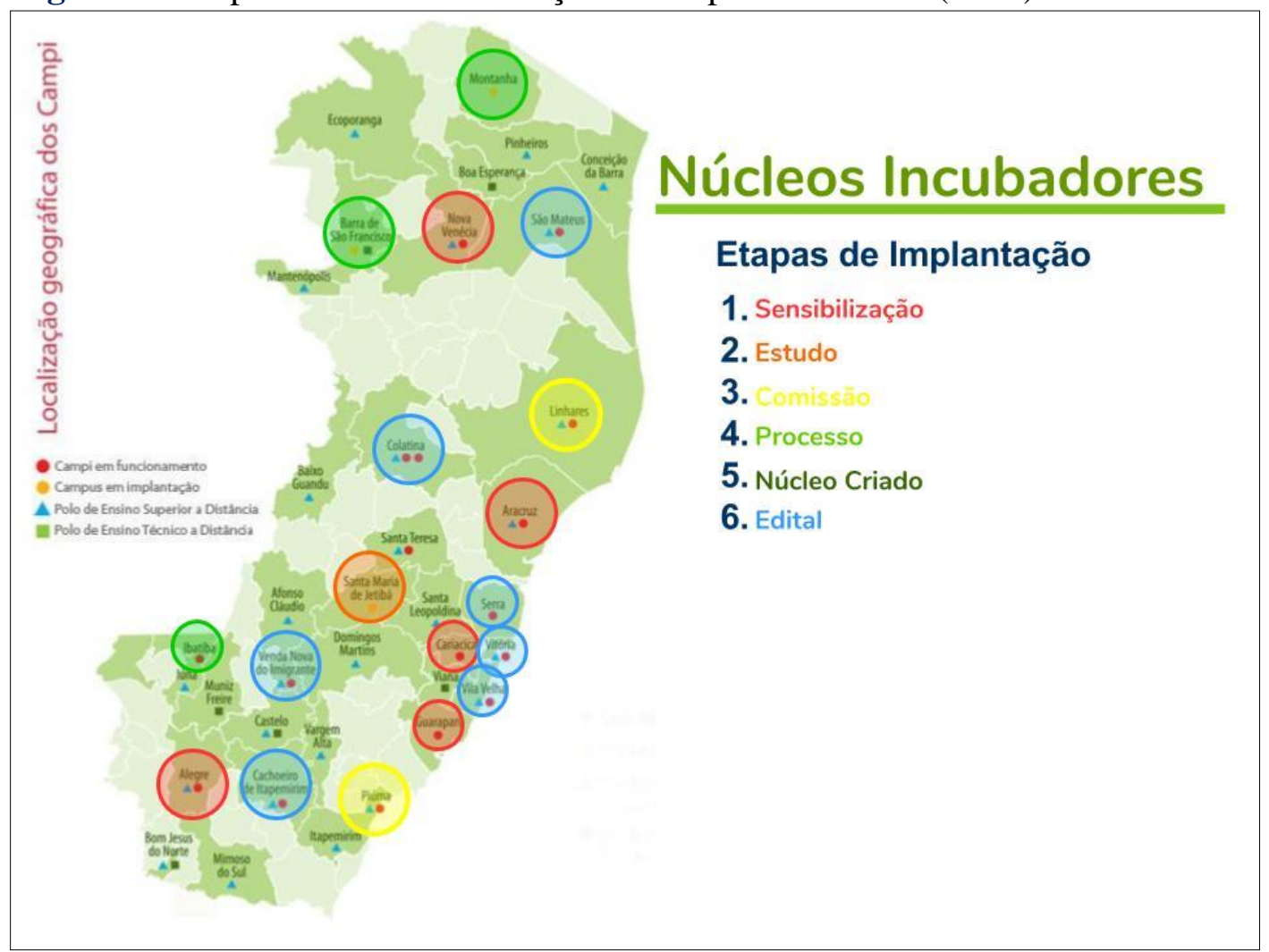

Fonte: Elaborado pelos autores (2017).

Em consonância com o mapa, descrevem-se os núcleos incubadores participantes desta pesquisa, visto que estão todos institucionalizados (em azul), e em funcionamento:

Núcleo Incubador - Campus Serra: Pioneiro desta rede começou os trabalhos em 2007, e recentemente graduou 02 (dois) empreendimentos, atua focado no eixo de base tecnológica;

Núcleo Incubador - Campus Vitória: apesar de estar localizado na Capital do estado, é um dos mais recentes, pois seu funcionamento começou no presente ano (2017) dentro da Fábrica de Ideias de Vitória, atua nos eixos de base tecnológica, social e economia criativa;

Núcleo Incubador - Campus Vila Velha: Trabalha em parceria com a "Incubadora Insight” do CEET Vasco Coutinho (Colégio Estadual), situado na Região Metropolitana de Vitória, atua nos eixos de base tecnológica (biotecnologia, química), social e economia criativa;

Núcleo Incubador - Campus Venda Nova do Imigrante: Iniciou suas atividades em 2015, encontra-se localizado na região serrana do Espírito Santo, atua mais focado em oferecer apoio a empreendimentos de agronegócios, agroturismo e associações da sociedade civil, bem como suporte às Indicações Geográficas; 
Núcleo Incubador - Campus Cachoeiro do Itapemirim: Situado na região sul do Espírito Santo, oferece apoio a empreendimentos de base tecnológica, social e economia criativa, mas atua com foco em impulsionar inovações no setor de mármore e granito, bem como apoiar Indicações Geográficas;

Núcleo Incubador - Campus São Mateus: Localizado na região norte do Espírito Santo, trabalha com empreendimentos de base tecnológica, social e economia criativa.

Núcleo Incubador - Campus Colatina: Localizado na região Noroeste do Espírito Santo, trabalha com empreendimentos de base mista.

\section{Análise dos resultados}

A análise realizada pelo software IRAMUTEQ encontrou 434 segmentos de textos analisáveis e considerados na classificação hierárquica descendente (CHD). O método da Classificação Hierárquica Descendente (CHD) classifica os segmentos de texto em função dos seus respectivos vocabulários, e o conjunto deles é repartido com base na frequência das formas reduzidas. As UCE identificam a quantidade de palavras, frequência média, pesquisam o vocabulário, reduzem as palavras com base em suas raízes (lematização), criam dicionário de formas reduzidas e identificam formas ativas e suplementares (CAMARGO; JUSTO, 2013a).

Os segmentos de texto foram compostos por 2.434 palavras que ocorreram 15.604 vezes, uma média de 6 vezes cada palavra, aproximadamente. A CHD dividiu o corpus em 5 classes, resultando no dendograma apresentado na Figura 3. 
Figura 3 - Dendograma da classificação hierárquica descendente do corpus FCS

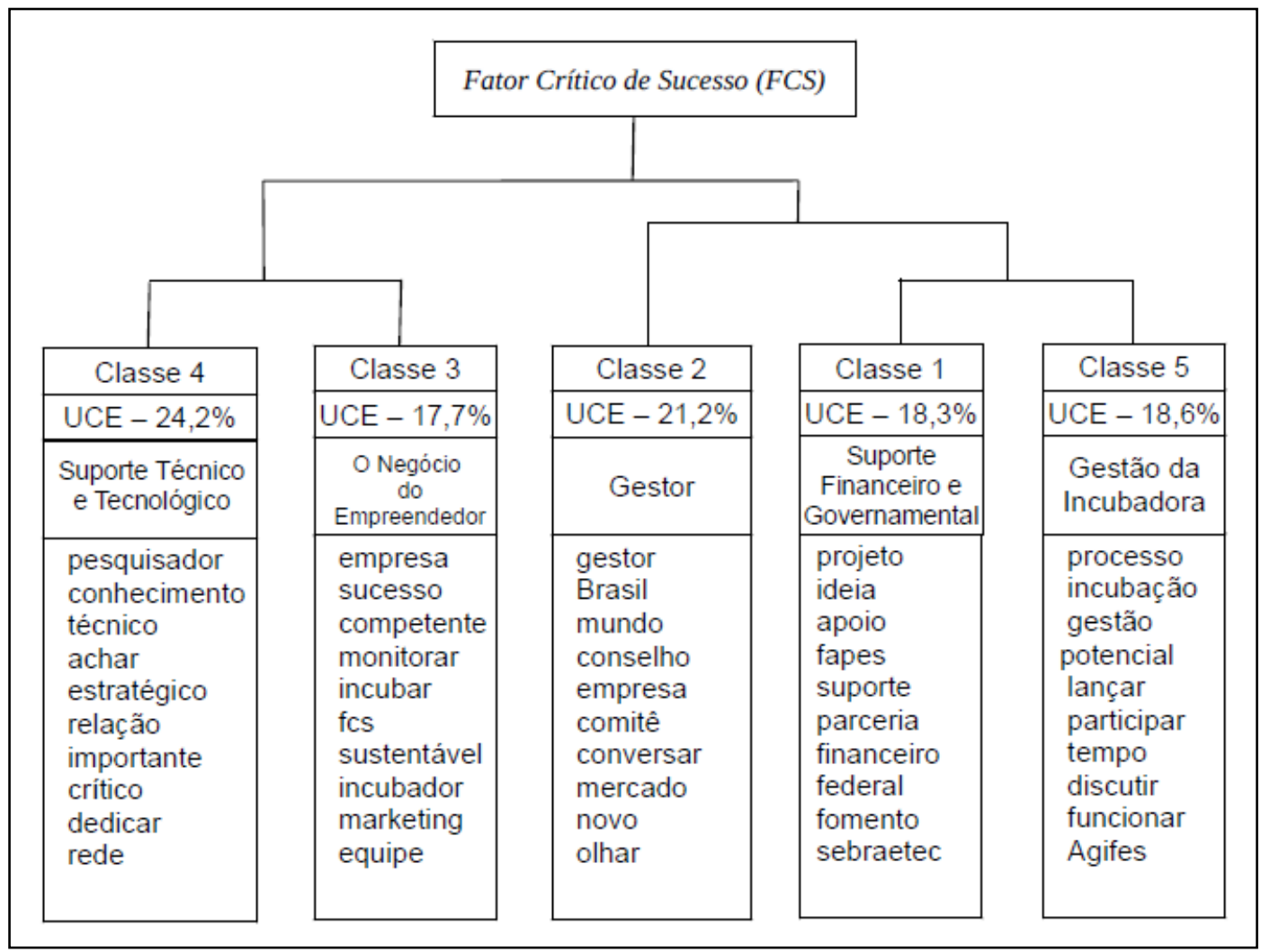

Fonte: Software IRAMUTEQ (2014).

A classe 4 denominada de "Suporte Técnico e Tecnológico" reúne 24,2\% das UCE (Unidades de Contexto Elementares). Seus principais elementos são: pesquisador, conhecimento, técnico, estratégico.

Fica evidente a importância do apoio da instituição, cedendo seus pesquisadores para atuarem nas empresas que estão incubadas na rede de incubação do Ifes. Essa visão de fora do pesquisador trás muitos benefícios e ajuda o empreendedor a desenvolver seu negócio e aprimorar novas técnicas. Algumas falas apontam para isso:

Principalmente em 2010, que tivemos o apoio da instituição que cedeu um pesquisador que ajudou, e muito, no desenvolvimento do nosso produto (Entrevistado 8).

Sim, cada colaborador tem um conhecimento diferente, uma visão diferente e uma outra experiência para passar aos empreendedores (Entrevistado 1).

Então eu acredito que o principal fator crítico de sucesso da incubadora no Campus Serra é essa possibilidade de fazer ponte com pesquisadores. Os empreendimentos fazerem pontes com esses pesquisadores. Então observe, não são necessariamente pesquisadores do instituto e muito menos do campus, mas a rede de relacionamentos que a incubadora ofereceu foi fundamental. Sem esses dois pesquisadores as empresas não teriam resolvidos 
esses problemas técnicos. Eu acho que o segundo fator crítico foi o aporte de gestão. Então esse primeiro seria esse aporte tecnologico, que permitiu essa relação com os pesquisadores que trouxeram essa bagagem significativa de conhecimentos tecnológicos e o segundo esse aporte técnico e de gestão (Entrevistado 6).

A classe 3 denominada de "O negócio do empreendedor" reúne 17,7\% das UCE (Unidades de Contexto Elementares). Seus principais elementos são: empresa, sucesso, incubar, monitorar.

Podemos observar como o processo de incubação é necessário para o negócio do empreendedor. A incubadora deve auxiliar e dar suporte para o empreendimento, desde a fase de elaboração do plano de negócios até a fase final do processo, quando a empresa tem seu portfólio definido e está apta a se graduar e ir para o mercado. Um acompanhamento periódico faz com que os empreendimentos criem suas rotinas e sejam mais doutrinados na sua gestão. Alguns trechos demonstram isso:

(...) já tem um negócio, e eles querem desenvolver outras ideias, ou que tem dificuldades de gerir sua própria empresa, que está tomando grandes proporções e os empresários não estão sabendo lidar, pois não são da área de gestão ou administração (Entrevistado 1).

A gente aqui tem alguns produtos tecnológicos que foram criados pela incubadora. Agora, se a gente não tiver mecanismos que gerem esses produtos, inovações, emprego e renda, eu acho que perde um pouco a função da incubadora (Entrevistado 3).

Então você precisa ter um bom relacionamento até para promover o sucesso dos empreendimentos. Então é um fotor muito importante. É um processo demorado, mas acreditamos ser possível que as empresas consigam um bom desempenho e a incubadora consiga uma ajuda. Futuramente que gerem novas patente e novas pesquisas para o ifes (Entrevistado 9).

Eu tiro isso pelos empreendimentos incubados, da necessidade de estar acompanhando e ver que eles estão sempre precisando desse acompanhamento, de perguntar como funciona (Entrevistado 2).

Tem que estar avaliando sempre o retorno do empreededor, quais os benefícios do seu empreendimento para a sociedade. A incubadora precisa ter um acompanhamento sistematizado e implantado. Nem que seja um acompanhamento trimestral e um monitoramento contínuo (Entrevistado 7).

A classe 2 denominada de "Gestor da Incubadora" reúne 21,2\% das UCE (Unidades de Contexto Elementares). Seus principais elementos são: gestor, Brasil, conselho, comitê. 
É valido afirmar que o gestor de uma incubadora é a pessoa mais apta a conduzir sua organização ao sucesso. Deve estar à frente de todos os processos da incubadora, precisa realizar as atividades com muito afinco e atenção para não comprometer os mesmos. Sendo assim, para que o gestor realize uma boa gestão ele precisa contar com um grupo de pessoas previamente escolhidas, para fazer parte do comitê gestor da incubadora.

No Brasil de todas as incubadoras que deram certo e que eu tive contato são a marca dos seus gestores. São os gestores que deram certo. Não existe uma incubadora que deu certo e que seu gestor era ruim (Entrevistado 6).

O gestor precisa se relacionar, tem que sair um pouco da academia e ter mais contato com o mundo empresarial (Entrevistado 2).

(...) dependendo da forma como o gestor gerencia, se ele não for um cara que "pega o boi pelo chifre", e não envolve com as questões de inovações e não tem um perfil de gestão, não está capacitado, isso impacta diretamente nos empreendimentos e nas situações decisórias de sucesso da incubadora e dos empreendimentos (Entrevistado 7).

(...) se não tiver (comitê gestor) a gente não consegue fazer nada, tem que ser participativa. No nosso caso é um dos poucos núcleos incubadores que tem essa questão participativa tão forte dentro do núcleo incubador do comitê gestor (Entrevistado 5).

A gestão do nosso núcleo incubador funciona com um comitê gestor e um coordenador. Até o momento essa gestão tem sido harmoniosa, geralmente acontecem reuniões bimestrais para prestação de contas e alinhamento de ações futuras (Entrevistado 10).

A classe 1 denominada de "Suporte Financeiro e Governamental" reúne 18,3\% das UCE (Unidades de Contexto Elementares). Seus principais elementos são: projeto, apoio, suporte, financeiro.

As incubadoras, principalmente as públicas, dependem fortemente de suporte financeiro e de apoio do governo para manter suas atividades. Logo, para que as incubadoras consigam se desenvolver, apoiar seus projetos que estão incubados, se faz necessário um aporte financeiro da sua instituição mantenedora e do governo através de editais de fomento que o governo disponibiliza. Diversos trechos expõem essa necessidade das incubadoras:

Nós temos o apoio do governo federal através do Ifes, mas nós também temos por exemplo a questão da Fapes, dos editais, de apoio a incubadora que foi fundamental (...) (Entevistado 5).

É, você tem que ter um patrocinador. No nosso caso é o governo federal através do recurso do próprio campus né. A captação de recursos é algo fundamental. A pessoa que vai tocar 
uma incubadora uma das primeiras coisas que ele deve aprender é captar recursos para dentro da incubadora (...). Então assim, a incubadora também deve captar e essa captação se dá muito na esfera pública, através de editais, através de balcões e através de ementas parlamentares, e assim por diante e não tem como viver sem (Entrevistado 6).

(...) e que já houve essa abertura para os institutos inovarem, já teve vários editais, tanto federal quanto estadual, através dos órgãos, FAPES, Finep, Cnpq. Então existe apoio (Entrevistado 2).

(...) o outro ponto da incubadora que eu considero é a busca por captação de recursos e o apoio financeiro que a instituição promove no sentido de subsidiar o espaço fisico e de subsidiar os cursos dos empreendimentos incubados (Entrevistado 7).

A classe 5 denominada de "Gestão da Incubadora" reúne 18,3\% das UCE (Unidades de Contexto Elementares). Seus principais elementos são: processo, incubação, gestão, tempo.

Uma incubadora possui diversos processos que precisam ser geridos e sistematizados. Sendo assim, a gestão das atividades e do tempo, o gerenciamento das empresas incubadas se tornam essenciais para que o sucesso aconteça. Alguns extratos que demonstram isso:

(...) mas também principalmente com quem dá esse suporte, no caso os professores que não estão direto na gestão mas que também atuam nas atividades e principalmente com a gestão que querendo ou não nós dependemos das decisões da gestão e da boa vontade dos gestores em investir na incubadora (Entrevistado 5).

O nosso trabalho aqui é algo a mais do que fazemos pela instituição, e muitas vezes a gente não consegue ter uma flexibilização da coordenadoria para a gente poder estar aqui. $\mathrm{O}$ gestor conseguiu que os colegas se sensibilizassem para que ele pudesse estar aqui. O que a gente sempre fala mesmo é essa questão do tempo mesmo disponível para atuar nas atividades da incubadora (Entrevistado 4).

Sabe-se que a maioria dos docentes dispostos a ajudar, estão envolvidos em várias demandas, além das aulas que já ministram, portanto acredito que será um fator limitador para o crescimento da incubadora (Entrevistado 10).

(...) é a quantidade de gente para estar disponível na incubadora e a qualificação desse pessoal, não só da gestão, mas principalmente da gestão, no sentido da capacitação e cursos voltados à gestão de incubadoras (Entrevistado 5).

Foi possível perceber a presença de um número expressivo de categorias e subcategorias que compõem o ambiente das incubadoras de empresas. Desse modo, viu-se necessário criar um modelo dos fatores críticos de sucesso voltado para a realidade da rede de incubação de 
empreendimento do Instituto Federal do Espírito Santo. A Figura 4 abaixo apresenta este modelo:

Figura 4 - Fatores Críticos de Sucesso das incubadoras do Espírito Santo

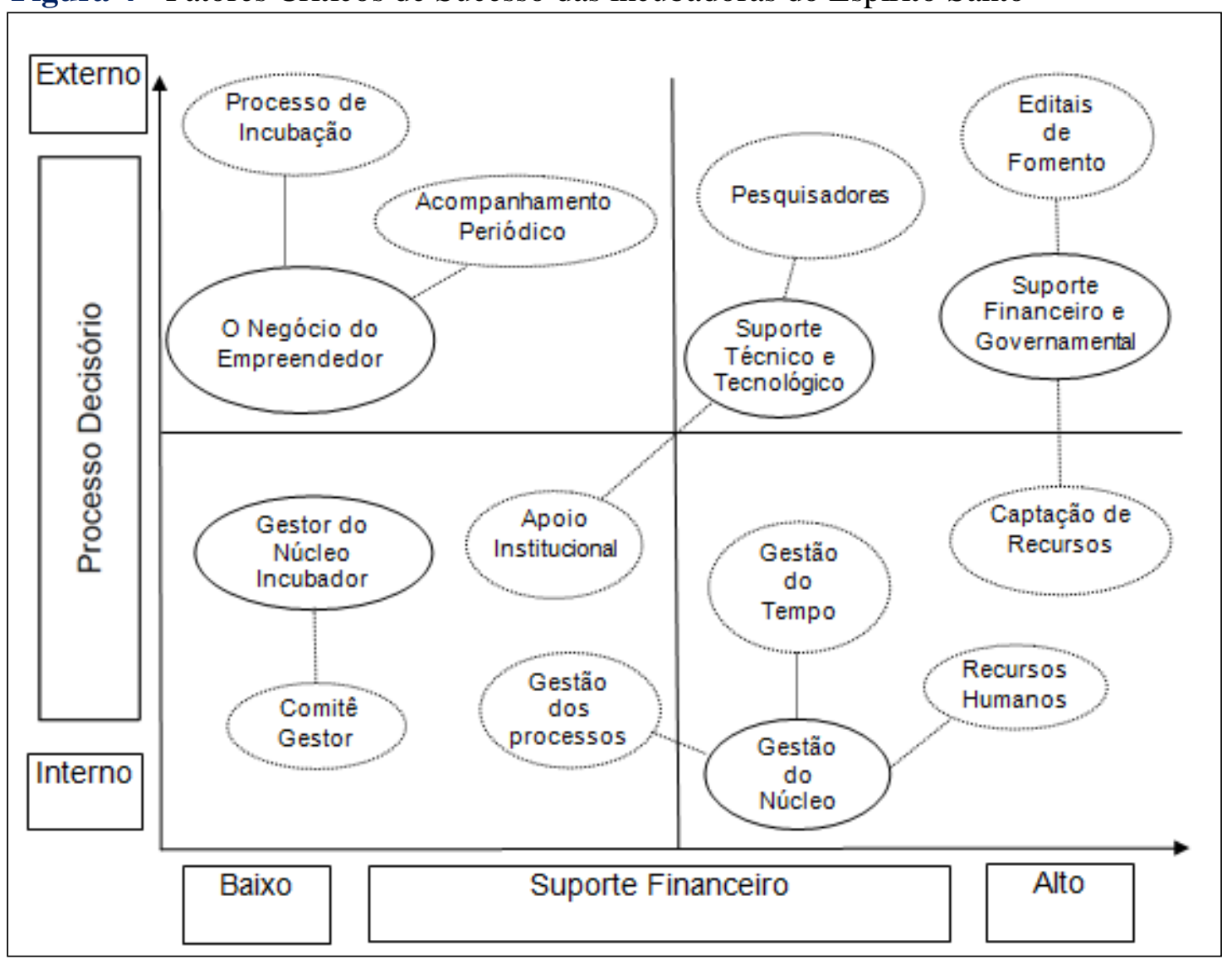

Fonte: Elaboração própria (2017).

Podemos observar na Figura 4 que os fatores críticos de sucesso possuem outras variáveis que influenciam e que também são críticas. Por isso estão com a circunferência tracejada. Têm ligação direta com os fatores críticos pois são importantes para o desempenho e o bom funcionamento de uma incubadora.

Alguns fatores críticos de sucesso possuem afinidade, quando comparado, por exemplo, quanto ao suporte financeiro da incubadora. O gestor do Núcleo incubador possui baixa dependência financeira e as decisões são tomadas todas internamente à incubadora, assim como o comitê gestor que presta seu trabalho de forma voluntária.

Outros fatores críticos de sucesso, como a gestão dos processos do núcleo incubador e o apoio institucional do Ifes, também fazem parte dos fatores que dependem pouco financeiramente da incubadora, e suas decisões estão sujeitos a atores externos. 
O negócio do empreendedor está intimamente ligado ao processo de incubação do núcleo e ao acompanhamento periódico que deve ser feito nas empresas que estão incubadas. Por serem fatores ligados internamente ao núcleo incubador, possui baixa dependência financeira, mas seu poder de decisão compete aos seus sócios que estão ainda ligados ao núcleo mas também ao mercado externo.

A gestão do núcleo incubador, assim como a gestão do tempo disponível para se dedicar as atividades, estão fortemente ligadas a aspectos internos. O quadro de pessoal também faz parte deste grupo que possuem uma moderada dependência financeira, pois o dispêndio de tempo e trabalho se tornam onerosos para o núcleo.

O último bloco é composto por fatores críticos que possuem alto suporte financeiro, e seus processos decisórios não competem somente à incubadora. Por isso, são considerados vitais. O suporte técnico e tecnológico oferecido pelos pesquisadores e suporte financeiro e governamental através dos editais e captação de recursos fazem parte deste bloco.

\section{Conclusões e recomendações}

O percurso dessa pesquisa permitiu uma ampla visão da rede de incubação de empreendimentos do Ifes. O propósito do estudo foi identificar fatores críticos de sucesso da rede de incubação de empreendimentos do Ifes. Para que isso fosse possível, o estudo de caso único aconteceu com todos os núcleos incubadores do Ifes que estão em funcionamento e institucionalizados, tendo os gestores, empreendedores incubados, e pessoas ligadas a rede de incubação como sujeitos da pesquisa. Os entrevistados, por estarem atuando sobre óticas diferentes, puderam perceber os fatores críticos em distintas perspectivas, contribuindo ainda mais para a pesquisa. A percepção de quem está gerindo o núcleo incubador é diferente de quem está estruturando uma empresa dentro dele.

A partir da análise do conteúdo das entrevistas, pode-se fazer inferências com relação aos FCS da rede de incubação de empreendimentos do Ifes. Alguns FCS possuíam afinidades quanto a sua categorização. Por isso, foi necessário estruturar os fatores encontrados em dois eixos: suporte financeiro e processo decisório.

Ao realizar a pesquisa, percebeu-se nas falas dos entrevistados a dependência financeira da incubadora para manter suas atividades em funcionamento. Além disso, também foi observado que alguns fatores tinham mais ligação com as atividades internas dos núcleos incubadores e por isso mais dependentes, e outros fatores que eram externos as atividades e possuíam pouca dependência nas ações ligadas à incubadora.

Entre os fatores identificados está o financiamento via editais de fomento. A FAPES 
(Fundo de Amparo à Pesquisa do Espírito Santo) tem apoiado a incubadora do Ifes e lançado editais específicos para a criação e desenvolvimento dos núcleos incubadores, visando contribuir com os empreendimentos incubados no desenvolvimento de inovação, e beneficiar a gestão das incubadoras a ajudar o estado a gerar mais inovação. É importante que a rede de incubação trabalhem em conjunto com essas instituições de fomento para que tenham suporte e mantenham suas atividades em funcionamento.

Apoio institucional, no que diz respeito aos recursos humanos disponibilizados para trabalhar na rede, também foi citado como um fator crítico de sucesso. É necessário pessoas que tenham conhecimento em gestão de incubadoras. Alocar pessoas para trabalhar ou gerir um núcleo incubador, é primordial para que os trabalhos possam ser executados e a incubadora consiga ter sucesso e atender com êxito toda sua rede. Além disso, observou-se que a rotatividade de gerência dificultam os trabalhos. A não falta de dedicação exclusiva aos trabalhos nos núcleos incubadores também afeta a execução das tarefas do dia a dia.

Porém, a rede de incubação de empreendimentos do Ifes têm problemas com quadro de pessoal, pois precisam em alguns casos alocar professores e funcionários para atuarem nos núcleos sem possuírem conhecimento necessário. Soma-se a isso, a carga horária elevada destes profissionais destas pessoas, o que resulta que acabam na falta de tempo suficiente não tendo tempo para executar suas atividades.

O papel do gestor do núcleo incubador é um fator crítico de sucesso tanto para os núcleos incubadores quanto para os empreendimentos incubados. É válido afirmar que um núcleo incubador só obtém sucesso se o seu gestor consegue controlar os processos e faz com que empreendimentos que estão incubados se insiram no vão para o mercado com solidez e confiança sólidos e confiantes. O gestor também precisa ter um perfil empreendedor, ser articulado, proativo e ter habilidade facilidade em construir e gerenciar redes de relacionamentos.

Destaca-se ainda mais um fator crítico que emergiu da pesquisa: o processo de incubação. Para que um núcleo incubador seja bem-sucedido, precisa vivenciar e acompanhar a rotina dos empreendimentos incubados. Esse acompanhamento evita problemas e assim o gestor ajuda os empresários nas decisões. As experiências com os empreendimentos incubados criam uma atmosfera empreendedora dentro dos núcleos. Com o tempo, os empreendedores tornam-se capazes de gerir seus negócios sozinhos, ficam mais propensos a criarem produtos inovadores, e aprendem a identificar oportunidades no mercado, tornando-os bem-sucedidos.

Foi identificado que o projeto de criação de um núcleo incubador deve contar com um 
regimento interno que prevê a composição de um comitê gestor para apoiar as atividades e processos existentes no núcleo. Logo, faz-se necessário a presença de um comitê gestor ativo, para conseguir deliberar as ações e cumprir as metas.

Por fim, e não menos importante, um outro fator crítico de sucesso identificado foi o suporte técnico e tecnológico oferecidos aos empreendimentos incubados por meio dos pesquisadores do próprio Ifes e de outras instituições. Estes pesquisadores são considerados essenciais, pois participaram do desenvolvimento dos produtos das empresas incubadas, além de oferecerem novos olhares e perspectivas para o desenvolvimento do empreendimento.

Pelos resultados acima apresentados, destacam-se algumas contribuições da presente pesquisa. Os FCS são essenciais para o desempenho e gestão da rede de incubação de empreendimentos do Ifes. A identificação desses fatores é uma ferramenta de apoio aos gestores desses empreendimentos, contudo o gerenciamento dos FCS traz contribuições práticas para todos os envolvidos seja no planejamento, seja ou na gestão da rede.

Para os núcleos incubadores que fizeram parte do estudo, e dos outros que estão sendo institucionalizados, segundo a fala dos próprios entrevistados, a pesquisa busca contribuir para que possam repensar algumas de suas ações e ampliar outros fatores que antes não eram observados. Este estudo pode se tornar um apoio para orientar ações e decisões, já que conforme observado nas entrevistas, alguns gestores raramente observam verificam esses fatores, ou os analisam de maneira informal.

Nesse sentido, a realização de estudos futuros poderá complementar as discussões sobre o tema. Uma das sugestões é realizar esse estudo dos fatores críticos de sucesso em outras regiões do Brasil, onde exista uma rede de incubação parecida com similar a do Ifes, possibilitando uma análise comparativa dos resultados. Assim, poderia se questionar até que ponto as diferenças entre os FCS alterariam o grau de importância de determinados fatores críticos e, também, onde e como ocorrem as principais influências desses fatores.

Pelo exposto, entende-se que o objetivo geral, de identificar os fatores críticos de sucesso da rede de incubação de empreendimentos do Ifes, segundo a percepção dos gestores, empreendedores incubados e pessoas ligadas a rede de incubação, foi plenamente atingido. Espera-se com esse trabalho, poder contribuir com as discussões acadêmicas e políticas sobre a implantação de uma rede de incubação de empreendimentos no apoio ao empreendedorismo e inovação, bem como, com a prática de gestão de incubadoras de empresas. E que essas questões da pesquisa contribuam com o desenvolvimento socioeconômico do estado do Espírito Santo. 


\section{Referências}

Aernoudt, R. (2004). Incubators: tool for entrepreneurship? Small Business Economics, 23(2), 127-135. https://doi.org/10.1023/B:SBEJ.0000027665.54173.23.

Al-Mubaraki, H. M., \& Busler, M. (2011). The Development of entrepreneurial companies through business incubator programs. International Journal of Emerging Sciences, 1(2), 95-107.

Anholon, R., \& Silva, M. C. (2015). Features of management system developed by a references business incubator: the case of Celta Florianópolis. Revista GEINTEC, 5(1), 1864-1880. https://doi.org/10.7198/S2237-0722201500010021.

Anprotec. (2015). Associação Nacional de Entidades Promotoras de Investimentos de Tecnologias Avançadas. http://www.anprotec.org.br.

Anprotec. (2016). Estudo de impacto econômico: segmento de incubadoras de empresas do Brasil / Associação Nacional de Entidades Promotoras de Empreendimentos Inovadores. Brasília, DF. http://www.anprotec.org.br/Relata/18072016\%20Estudo_ANPROTEC_v6.pdf.

Armbruster, H., Bikfalvi, A., Kinkel, S., \& Lay, G. (2008). The challenge of measuring nontechnical innovation in large-scale surveys. Technovation, 28(10), 644-657. https://doi.org/10.1016/j.technovation.2008.03.003.

Barbosa, C. F., Nascimento, M. V., Santos, A. M. L. B., Ribeiro, A. R. B., \& Silva, F. F. (2014). Análise dos fatores que contribuem para o sucesso ou insucesso de empresas de base tecnológica (EBTS) incubadas: Um estudo multicasos em incubadoras de Pernambuco. Anais do Encontro Nacional de Engenharia de Produção, Curitiba, PR, Brasil.

Bardin, L. (2004). Análise de conteúdo (3a. ed.). Lisboa: Edições.

Baron, R. A., \& Tang, J. (2011). The role of entrepreneurs in firm-level innovation: Joint effects of positive affect, creativity, and environmental dynamism. Journal of Businees Venturing, 26(1), 49-60. https://doi.org/10.1016/j.jbusvent.2009.06.002.

Bollingtoft, A. (2012). The bottom-up business incubator: Leverage to networking and cooperation pratices in a self-generated, entrepreneurial-enabled environment. Technovation, 32(5), 304-315. https://doi.org/10.1016/j.technovation.2011.11.005.

Lei n. 10.973, de 2 de dezembro de 2004 (2004). Dispõe sobre incentivos à inovação e à pesquisa científica e tecnológica no ambiente produtivo e dá outras providências. Brasília, DF. http://www.planalto.gov.br/ccivil_03/_ato2004-2006/2004/lei/110.973.htm.

Bruneel, J., Ratinho, T., Clarysse, B., \& Groen, A. (2012). The evolution of business incubator: Comparing demand and supply of business incubation services across different incubator generations. Technovation, 32(2), 110-121. https://doi.org/10.1016/j.technovation.2011.11.003. 
Buys, A. J., \& Mbewana, P. N. (2007). Key success factors for business incubation in South Africa: the Godisa case study. South African Journal of Science, 103(9/10), 356-358. http://www.scielo.org.za/pdf/sajs/v103n9-10/a0110310.pdf.

Carmo, J. P., \& Costa, L. (2016). Análise da sustentabilidade econômica de um núcleo de inovação tecnológica integrado a uma incubadora de empresas. Anais do Congresso de Administração Sociedade e Inovação, Minas Gerais, MG, Brasil.

Castro, B. S., \& Souza, G. C. (2012). O papel dos Núcleos de Inovação Tecnológica (NITs) nas universidades brasileiras. Liinc em Revista, 8(1), 125-140. https://doi.org/10.18617/liinc.v8i1.465.

Corsani, A. (2003). "Elementos de uma ruptura: a hipótese do capitalismo cognitivo" in Galvão, Alexander P. et al. Capitalismo cognitivo: trabalho, redes de inovação Rio de Janeiro, DP\&A Editora.

Dornelas, J. C. A. (2012). Planejando incubadoras de empresas: como desenvolver um plano de negócios para incubadoras (2a. ed.). Rio de janeiro: Campus.

Etzkowitz, H., Mello, J. M. C., \& Almeida, M. (2005). Towards "meta-innovation" in Brazil: the evolution of the incubator and the emergence of a triple helix. Research Policy, 34(4), 411-424. https://doi.org/10.1016/j.respol.2005.01.011.

Fitjar, R. D., \& Rodríguez-Pose, A. (2013). Firm collaboration and modes of innovation in Norway. Research Policy, 42(1) 128-138. https://doi.org/10.1016/j.respol.2012.05.009.

Fortec. (2015). Fórum nacional de gestores de inovação e transferência de tecnologia. Relatório Anual FORTEC 2014-15. Brasília, DF. http://fortec.org.br/wpcontent/uploads/2016/05/FORTEC-Relatorio-2014-16-em-160516publicado-corr1.pdf.

Fujino, A., Stal, E., \& Plonski, G. A. (1999). A proteção do conhecimento na universidade. RAUSP Management Journal, 34(4), 46-55. http://www.spell.org.br/documentos/ver/18139/a-protecao-do-conhecimento-na universidade/i/pt-br.

Gillotti, T., \& Ziegelbauer, R. (2006). Seven components of a successful business incubator. University of Wisconsin Extension. Let's Talk Business, 119.

Gozali, L., Masrom, M., Zagloel, T. Y. M., \& Haron, H. N. (2016). A framework of successful business incubators for indonesian public universities. International Journal of Technology, 7(6), 1086-1096. https://doi.org/10.14716/ijtech.v7i6.3351.

Lalaka, R. (1996). Technology business incubators: Critical determinants of success. Annals of The New York Academy of Sciences: Nova York.

Lee, S. S., \& Osteryoung, J. S. (2004). A comparison of critical success factors for effective operations of university business incubators in the United States and Korea. Journal of Small Business Management, 42(4), 418-426. https://www.tandfonline.com/doi/abs/10.1111/j.1540-627X.2004.00120.x. 
Maletz, E. A., \& Siedenberg, D. R. (2007). A Gestão dos Fatores Críticos de Sucesso nas Incubadoras de Empresas da Região do Ruhr - Alemanha. Anais do EnANPAD, Rio de Janeiro, RJ, Brasil.

Martínez-Román, J. A., Gamero, J., \& Tamayo, J. A. (2011). Analysis of innovation in SME's using an innovative capability-based non-linear model: A study in the province of Seville (Spain). Technovation, 31(9), 459-475. https://doi.org/10.1016/j.technovation.2011.05.005.

Ministério da Ciência e Tecnologia e Inovação - MCTI. Parques \& Incubadoras para o Desenvolvimento do Brasil: Estudos de Impactos do PNI: Programa Nacional de Apoio a Parques Tecnológicos e Incubadoras de Empresas/Ministério de Ciência, Tecnologia e Inovação - MCTI; Brasília, DF.

Morioka, S., \& Carvalho, M. M. (2014). Análise de fatores críticos de sucesso de projetos: um estudo de caso no setor varejista. Production, 24(1), 132-

143. https://doi.org/10.1590/S0103-65132013005000015.

Pyka, A. (2000). Informal networking and industrial life cycles. Technovation, 20, 25-35.

Nelson, R. R. (1993). National innovation systems: a comparative analysis. New York: Oxford University Press, 541.

Ortigara, A. A., Grapeggia, M., Juliatto, D. L., \& Bastos, R. C. Análise por agrupamento de fatores de desempenho das incubadoras de empresas. Revista de Administração e Inovação, 8(1), 64-91. https://doi.org/10.5773/rai.v8i1.390.

Padrão, L. C. (2011). Fatores críticos de sucesso no desenvolvimento de produtos de empresas de base tecnológicas. Tese de Doutorado em Administração de Empresas Faculdade Getúlio Vargas, Escola de Administração de Empresas, São Paulo, SP, Brasil.

Ratinho, T., \& Henriques, E. (2010). The role of science parks and business incubators in converging countries: Evidence from Portugal. Technovation, 30(4), 278-290. https://doi.org/10.1016/j.technovation.2009.09.002.

Santos, M. E. R. (2009). Boas práticas de gestão em Núcleos de Inovação Tecnológica. In: Santos, M. E. R., Toledo, P. T. M., \& Lotufo, R. A. (Orgs.). Transferência de Tecnologia: estratégias para estruturação e gestão dos Núcleos de Inovação Tecnológica. Campinas: Komedi, 75-108.

Schumpeter, J. (1984). Capitalism, socialism and democracy. (1 ${ }^{\mathrm{a}}$. ed.). Harper, USA.

Smilor, R. W. (1987). Managing the incubator system: critical success factors to accelerate new company development. IEEE Transactions on Engineering Management, 34(3), 146155. https://doi.org/10.1109/TEM.1987.6498875.

Souza, A. C. M. M. (2011). Gestão de Núcleos de Inovação Tecnológica. Anais do Congresso Internacional IGLU, Florianópolis, SC, Brasil.

Sun, H., Ni, W., \& Leung, J. (2007). Critical Success Factors for Technological Incubation: Case Study of Hong Kong Science and Technology Parks. International Journal of Management, 24(2), 346-363. 
Tavoletti, E. (2013). Business incubators: effective infrastructures or waste of public money? looking for a theoretical framework, guidelines and criteria. Journal of the Knowledge Economy, 4(4), 423-443. https://doi.org/10.1007/s13132-012-0090-y.

Torkomian, A. L. V., \& Calligaris, A. B. (2003). Benefícios do desenvolvimento de projetos de inovação tecnológica. Revista Produção, 13(2), 21-32. https://doi.org/10.1590/S010365132003000200003.

Triguero, A., \& Córcoles, D. (2013). Understanding innovation: An analysis of persistence for Spanish manufacturing firms. Research Policy, 42(2), 340-352.

https://doi.org/10.1016/j.respol.2012.08.003. 